\title{
Sustaining PICA for future NASA Robotic Science Missions including NF-4 and Discovery
}

\author{
Mairead Stackpoole \\ NASA Ames Research Center \\ Moffett Field, CA 94035 \\ 650-604-6199 \\ Margaret.m.stackpoole.nasa.gov
}

\author{
Ethiraj Venkatapathy \\ NASA Ames Research Center \\ Moffett Field, CA 94035 \\ 650-604-4282 \\ ethiraj.venkatapathy- \\ 1@nasa.gov
}

\author{
Steven Violette \\ Fiber Materials Inc. \\ Biddeford, ME 04005 \\ 207-282-7062 \\ Steven.Violette@fibermaterialsinc.com
}

\begin{abstract}
Phenolic Impregnated Carbon Ablator (PICA), invented in the mid 1990's, is a low-density ablative thermal protection material proven capable of meeting sample return mission needs from the moon, asteroids, comets and other unrestricted class $V$ destinations as well as for Mars. Its low density and efficient performance characteristics have proven effective for use from Discovery to Flag-ship class missions. It is important that NASA maintain this thermal protection material capability and ensure its availability for future NASA use. The rayon based carbon precursor raw material used in PICA preform manufacturing has experienced multiple supply chain issues and required replacement and requalification at least twice in the past 25 years and a third substitution is now needed. The carbon precursor replacement challenge is twofold - the first involves finding a long-term replacement for the current rayon and the second is to assess its future availability periodically to ensure it is sustainable and be alerted if additional replacement efforts need to be initiated. This paper reviews current PICA sustainability activities to identify a rayon replacement and to establish that the capability of the new PICA derived from an alternative precursor is in family with previous versions.
\end{abstract}

\section{TABLE OF CONTENTS}

1. INTRODUCTION .1

2. PICA PRECURSOR SUPPLY CHAIN ..........................1

3. LYOCELL - A SUSTAINABLE PRECURSOR..............2

4. LYOCELL PICA MANUFACTURING ......................... 2

5. ARC JET TESTING .................................................3

6. MECHANICAL AND THERMAL TESTING .................. 4



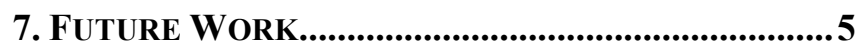

ACKNOWLEDGEMENTS .......................................6

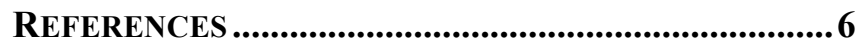

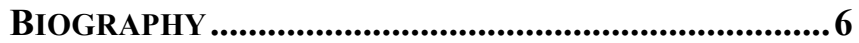

\section{INTRODUCTION}

PICA, invented in the mid 1990's [1] at NASA Ames Research Center, is the lowest density heritage carbonphenolic based ablative thermal protection system (TPS). The timely invention of PICA enabled the Stardust mission [2], the very first mission to bring back samples from outside the earth-moon system. During entry, the sample return capsule was protected from the heat by a single piece net cast PICA heatshield. OSIRIS REx, the first US mission to bring back samples from an asteroid (Bennu) to Earth, also uses a single piece PICA heatshield very similar to the Stardust design. In addition to Stardust and OSIRIS-REx, PICA was used as the heatshield on the Mars Science Lab (MSL) in a tiled configuration. The Mars 2020 mission heatshield design will follow that of MSL and again use PICA in a tiled arrangement. A variant of PICA known as PICA-X is used as the heatshield TPS on the Dragon capsule.

Based on successful mission use across destinations ranging from earth return to Mars, PICA has been proposed as the TPS option for numerous New Frontier and Discovery missions. PICA has also been proposed as the heatshield TPS for a Lunar Sample return mission and as a backshell material for missions such as Venus, Saturn and other destinations where the heating during entry requires a carbon-based ablator.

\section{PICA Precursor Supply Chain}

PICA is composed of a rigid carbon fiber based preform (derived from rayon) that is infused with a phenolic matrix. The rigid and somewhat fragile PICA is an uncomplicated ablative TPS system having limited constituents. Additionally, the PICA process is more straightforward than many low to mid density ablators allowing for a more uniform material. Fiber Materials Inc. produces carbon fiberform $^{\mathrm{TM}}$, a rigid, low density porous carbon foam like material, using a proprietary process from chopped carbon fibers. FMI manufactures carbon fibers from commercially available rayon by a high temperature conversion process allowing controlled removal of volatiles and graphitization. One of FMI's core product lines is the fiberform ${ }^{\mathrm{TM}}$ which is used as insulation liners for industrial ovens and other such applications. The PICA process involves infusing the carbon fiberform $^{\mathrm{TM}}$ with a lightweight phenolic resin matrix. The open porous nature of the fiberform ${ }^{\mathrm{TM}}$ is amenable to vacuum infusion processes. The phenolic resin infusion and curing yields a high surface area phenolic phase filling the void space between filaments resulting in an ablative TPS that has proven performance at heat-fluxes approaching $1500 \mathrm{~W} / \mathrm{cm}^{2}$ and stagnation pressures approaching $1 \mathrm{~atm}$.

U.S. Government work not protected by U.S. copyright 
In spite of the fact that PICA only has two constituents and a relatively straightforward process, it has faced multiple supply chain issues. The original PICA was manufactured using fiberform ${ }^{\mathrm{TM}}$ derived from Liberty rayon (a US based source). Liberty rayon manufacturing was discontinued in the mid 2000s'. Since the fiberform ${ }^{\mathrm{TM}}$ commercial product line depends on a rayon precursor, FMI evaluated an alternate rayon, Sniace, (a Spanish source). FMI completes the rayon conversion process in-house. Recently, FMI learned that Sniace rayon is no longer available. For their commercial products, FMI has started to evaluate alternate rayon from Asia. The fiberform ${ }^{\mathrm{TM}}$ requirements for commercial applications are less stringent than NASA requirements. Establishing a flight qualified ablator requires choosing the fiberform $^{\mathrm{TM}}$ from a precursor that is well characterized and having consistent constituents that are sustainable into the future. The end fiberform ${ }^{\mathrm{TM}}$ material needs to fall within the density and property specifications consistent with previous versions used in PICA. Extensive testing for thermal, ablation and recession performance are required once PICA is manufactured from a single fiberform precursor. In addition, the thermal and mechanical property database relied upon for sizing and design of the heat-shield needs to be verified or rebuilt when a precursor change is made. Any variability that results due to changes in the precursor source requires extensive testing as well as changes to establish manufacturing specifications to ensure the variations in properties and performance are well understood and within acceptable ranges.

\section{Lyocell - A Sustainable Precursor}

Traditional rayon manufactured from wood pulp involves many steps and the conversion of wood pulp into rayon or regenerated cellulose results in toxic byproducts. For this reason, rayon manufacturing was discontinued and is no longer a viable process in the US and Europe. In the early 80 's leading rayon producers, Courtaulds Fibres and American Enka, began investigating a new method of producing a cellulosic fiber through a solvent spinning technique and in this method cellulose is softened and spun into fibers. The solvent spinning technique is both simpler and more environmentally sound, since it uses a nontoxic solvent chemical that is $99 \%$ recycled in the manufacturing process. The solvent-spun cellulosic fiber lyocell [3] was first produced commercially in the United States in 1992 by Courtaulds. The company used the brand name Tencel ${ }^{\circledR}$. The fiber was given the generic name lyocell in the United States in 1996. By this time, there was one other major lyocell producer in the world, the Austrian company Lenzing AG, which had acquired patents and research on lyocell from American Enka when it bought that company's rayon operation in 1992. Austrian textile giant Lenzing bought the American counterpart in 2004 and currently manufactures lyocell with a brand name of Tencel ${ }^{\circledR}$ both in Germany and in the US in very large quantities [4]. The Tencel $^{\circledR}$ fibers are used in many different applications including medical products, clothing, baby wipes and diapers. Because of domestic manufacturing combined with very large commercial use, lyocell fibers are being evaluated by FMI for their fiberform ${ }^{\mathrm{TM}}$ product. Though they had initial success, the cost of lyocell compared with then available rayon from foreign suppliers was significant and FMI did not further pursue lyocell derived fiberform ${ }^{\mathrm{TM}}$. In early 2000, NASA Ames Research Center working with SoRI manufactured high density carbon phenolic using carbon yarn from lyocell and tested it. The recession performance compared favorably with both heritage carbon phenolic and carbon phenolic made with other rayon sources indicating that lyocell is a viable rayon alternative for TPS applications.

When FMI learned that the Sniace rayon used for MSL PICA was discontinued, they acquired a sufficient quantity in anticipation of PICA needs for the Mars 2020 mission. FMI informed NASA of the imminent supply chain issue. NASA then decided to secure the remaining Sniace rayon, convert to carbon and store for future SMD use. In addition, NASA started to evaluate if lyocell based PICA would be comparable to heritage PICA. FMI is currently working with NASA to evaluate lyocell based PICA as a future replacement.

\section{Lyocell PICA Manufacturing}

NASA recently awarded a contract to FMI to evaluate manufacturing lyocell derived PICA bounding the density specification. This effort was limited in scope and focused on establishing processing parameters and capturing changes from the current rayon fiberform process line. FMI has successfully manufactured a single piece net shape cast fiberform at the OSIRIS REx scale (Figure 1) as well as fiberform billets. The net casting allows a single piece of PICA to be manufactured into a heatshield while the billet form yields PICA blocks similar to those used in the MSL tiled PICA heatshield. The fiberform billets fabricated were used to conduct preliminary comparison testing between heritage and lyocell derived PICA as described in the following sections.



\section{Figure 1. Lyocell based net-casted fiberform (same} size as Stardust or OSIRIS-REx). 


\section{Arc Jet Testing}

Arc jet testing was recently performed in Ames Research Center's Interaction Heating Facility (IHF) and Aerodynamic Heating Facility (AHF). The primary test objectives were to compare the thermal response and recession behavior of lyocell derived PICA with rayon derived PICA and get an initial look at any performance differences or off-nominal behavior in the lyocell PICA. A $10.16 \mathrm{~cm}$ (4") iso-q test geometry was selected in order to access the characteristics of interest. The iso-q sphere-cylinder geometries have the sphere curvature radius equal to the diameter of the cylinder of the model. The model geometry and assembly is shown in Figure 2. Each coupon was instrumented with a plug containing 5 in-depth thermocouples consisting of 2 type-R and 3 type $\mathrm{K}$. The target test conditions are summarized in Table 1 . Test conditions were measured on a $10.16 \mathrm{~cm}$ radius iso-q slug calorimeter in all run cases.

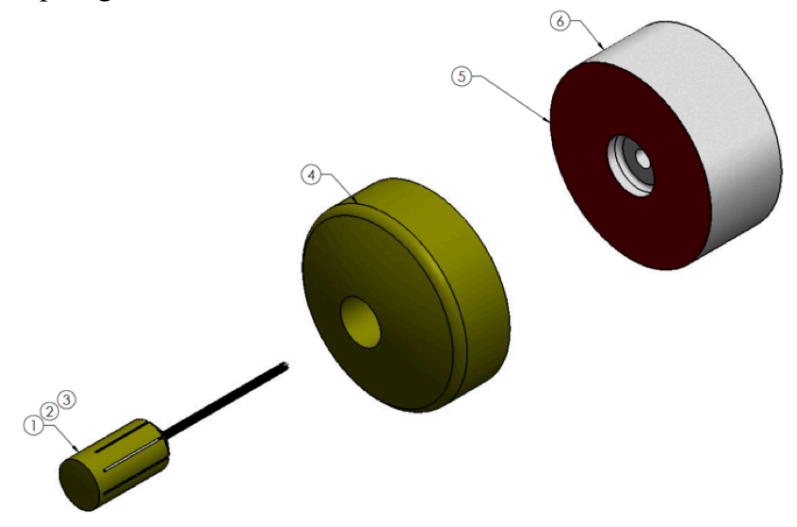

Figure 2. 4-in PICA iso-q model and assembly with thermocouple plug and LI2200 tile holder

Table 1. Summary of Are Jet Test conditions

\begin{tabular}{|l|l|l|}
\hline \multicolumn{1}{|c|}{$\begin{array}{c}\text { Target } \\
\text { Conditions }\end{array}$} & \multicolumn{1}{|c|}{ Objective } & \multicolumn{1}{c|}{ Comments } \\
\hline $\begin{array}{l}\sim 220 \mathrm{~W} / \mathrm{cm}^{2} \\
\text { and } 0.08 \text { atm } \\
(4 " \text { iso-q), } \\
\text { duration of } \\
10 \mathrm{sec}\end{array}$ & $\begin{array}{l}\text { Thermal } \\
\text { response, } \\
\text { recession }\end{array}$ & $\begin{array}{l}\text { Instrumented } \\
\text { coupon, } \\
\text { calibration } \\
\text { included. Tested } \\
\text { Oct 2017, }\end{array}$ \\
\hline $\begin{array}{l}\sim 400 \mathrm{~W} / \mathrm{cm}^{2} \\
\text { and } 0.3 \mathrm{~atm} \\
(4 " \text { iso-q), } \\
\text { duration of } \\
35 \mathrm{sec}\end{array}$ & $\begin{array}{l}\text { Thermal } \\
\text { response, } \\
\text { recession }\end{array}$ & $\begin{array}{l}\text { Instrumented } \\
\text { coupon. Tested } \\
\text { Aug 2017 }\end{array}$ \\
\hline $\begin{array}{l}\text { 1550W/cm } \\
\text { ans } 1.3 \mathrm{~atm} \\
(4 " \text { iso-q), } \\
\text { duration of } \\
45 \mathrm{sec}\end{array}$ & $\begin{array}{l}\text { Failure mode } \\
\text { evolution, } \\
\text { thermal } \\
\text { response, } \\
\text { recession }\end{array}$ & $\begin{array}{l}\text { Instrumented } \\
\text { coupon. Tested } \\
\text { Aug 2017 }\end{array}$ \\
\hline
\end{tabular}

Figure 3 compares the heritage and lyocell derived PICA articles pre- and post-test. Initial testing indicates comparable thermal response and centerline recession. Centerline recessions were measured by laser scanning the entire model assembly pre- and post-testing. The large 100 $\mathrm{mm}$ field of view resulted in a recession uncertainty of 0.2 $\mathrm{mm}$. At the lowest test condition, $220 \mathrm{~W} / \mathrm{cm}^{2}$ and $0.08 \mathrm{~atm}$, the average measured centerline recession for the rayon derived PICA material was $3.89 \mathrm{~mm}$ compared to $3.79 \mathrm{~mm}$ for the lyocell derived PICA indicating comparable performance. The in-depth thermocouple traces between both variants of PICA were also compared. For a given thermocouple depth the traces are very similar indicating comparable thermal response. An example thermocouple trace is provided in Figure 4 for for lowest test condition, $220 \mathrm{~W} / \mathrm{cm}^{2}$ and $0.08 \mathrm{~atm}$. Post-test analysis including comparison of thermal response of lyocell and rayon derived PICA using the PICA high-fidelity thermal response model is currently ongoing using the Fully Implicit Ablation and Thermal response program (FIAT) [5]. FIAT simulates onedimensional transient thermal energy transport in a material that can ablate from the top surface and decompose in-depth.



Pre-test rayon PICA



Post-test rayon PICA

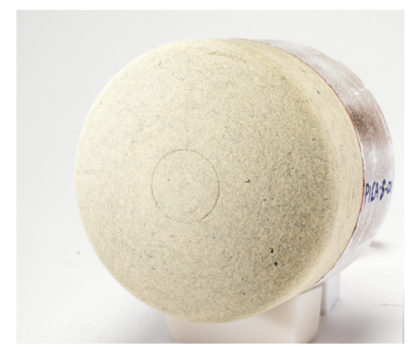

Pre-test lyocell PICA

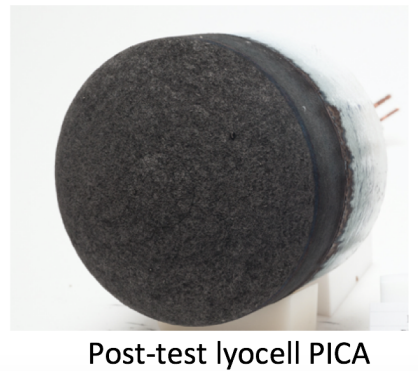

Figure 3. Pre- and post- arc jet tested heritage rayon (left) and lyocell (right)

Pyrometry measurements were also obtained to track surface temperature during the runs. The lyocell derived PICA was observed to have a surface temperature of $\sim 50 \mathrm{C}$ higher than the rayon derived models for the run duration. The increased lyocell surface temperature was observed on all runs. Postrun lyocell derived PICA char also had a slightly different hue than heriatge PICA. This result indicates that a possible contaminant in the lyocell derived material is influencing the surface emissivity. Subsequent chemical analysis completed on the lyocell and rayon fibers picked up a higher titanium content in the lyocell material. The Ti is added as a dulling agent to the lyocell fibers prior to spinning. Dulling agents 
are added to provide the fibers with certain asthetic properties. Titanium dioxide, a white dulling agent, is added in small amounts to provide the fiber with a "dull" appearance. The typical amount of titanium dioxide added is less that $1 \%$ [6]. Other versions of lyocell fiber without dulling agents are available and will be considered for future PICA precursor work. This unexpected result indicates the importance of characterizing the precursor materials and flagging any unacceptable contaminants.

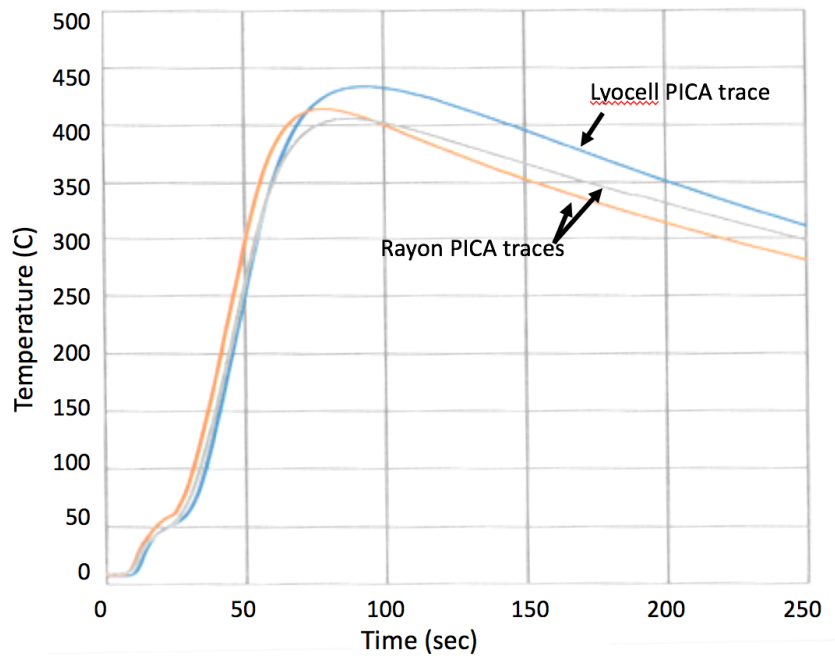

Figure 4. In-depth thermocouple trace comparing lyocell and rayon derived PICA $\left(220 \mathrm{~W} / \mathrm{cm}^{2}\right.$ and 0.08 atm, 45 second run time)

\section{Mechanical and Thermal Testing}

To support property testing three lyocell-based PICA billets were fabricated using the general specification for PICA tile components, incorporating the lyocell-based fiber precursor materials and some enhanced engineering controls. The billets were designated as LI-5, LI-6, and LI-7. From these materials, the following tests were conducted to compare them to heritage baseline PICA lot acceptance test (LAT) results: in-plane (IP) tension, through-thickness (TT) tension, and through thickness thermal conductivity at $100^{\circ} \mathrm{F}$ and $350^{\circ} \mathrm{F}$. The data was compared to Mars Science Laboratory and Mars 2020 production LAT results. The three lots tested were selected to represent the material's density varying through the range of specification limits on billet density, $0.26 \mathrm{~g} / \mathrm{cc}$ to $0.30 \mathrm{~g} / \mathrm{cc}$.

Tension testing of PICA material complied with ASTM E-4, "Verification of Testing Machines"; ASTM E-83, "Verification and Classification of Extensometers"; ASTM D 1623, Type B, "Standard Test Method for Tensile and Tensile Adhesion Properties of Rigid Cellular Plastics"; and FMI IPOS 08-02-04 Part M Revision A, "In-Plane and ThruThickness Orientation Tensile Testing Procedure for FMI PICA Materials". Test specimens were bonded to T6-6061 aluminum loading blocks using epoxy resin in an alignment fixture, and following cure were subsequently placed into the test equipment. Test equipment included an Instron Model 1115 Electromechanical 10,000 lb capacity test machine; Instron model 2511-301 1,000 lb. load cell; MTS model \# 632-59C-01 Elevated Temperature Contacting Extensometry System; and data acquisition computer system with National Instruments LabVIEW 2011 software.

Tension test results are presented in Table 2, listing specimen average density, failure load, failure stress, strain at failure, and modulus. Comparing these results to MSL/M2020 production data, average MSL/M2020 LAT measurements were: $0.278 \mathrm{~g} / \mathrm{cc}$ density, $190 \mathrm{psi}$ in-plane tension failure stress, and 49.6 psi through-thickness tension failure stress. lyocell-based PICA average results in Table 2 were: 0.279 $\mathrm{g} / \mathrm{cc}$ density, $246 \mathrm{psi}$ in-plane tension failure stress, and 44.0 psi through-thickness tension failure stress. Overall these results were very comparable LAT results for production PICA. The higher in-plane tension, a beneficial result, was attributable to the average fiber length being longer than in heritage materials, which was an effect of the enhanced engineering controls. No anomolies were identified in the minimum values of tension strength, variance of tension strength, or the other measurements presented in Table 2 with respect to heritage PICA test results.

Table 2. Summary of Lyocell Derived PICA Mechanical Properties

\begin{tabular}{|l|l|l|l|l|l|}
\hline & $\begin{array}{l}\text { Density } \\
\text { g/cc }\end{array}$ & $\begin{array}{l}\text { Failure } \\
\text { Load } \\
\text { lbs }\end{array}$ & $\begin{array}{l}\text { Failure } \\
\text { Stress } \\
\text { psi }\end{array}$ & $\begin{array}{l}\text { Strain } \\
\text { at } \\
\text { Failure } \\
\%\end{array}$ & $\begin{array}{l}\text { Modulus } \\
\text { ksi }\end{array}$ \\
\hline $\begin{array}{l}\text { Avg Lyocell } \\
\text { in-plane } \\
\text { properties }\end{array}$ & 0.28 & 986.16 & 246.48 & 0.30 & 96.69 \\
\hline $\begin{array}{l}\text { Avg Rayon } \\
\text { in-plane } \\
\text { properties }\end{array}$ & 0.278 & 176.24 & 44.03 & 0.77 & 6.92 \\
\hline $\begin{array}{l}\text { Avg Lyocell } \\
\text { TTT } \\
\text { properties }\end{array}$ & 0.28 & 190 & & \\
\hline $\begin{array}{l}\text { Avg Rayon } \\
\text { TTT } \\
\text { properties }\end{array}$ & 0.278 & & 49.6 & & \\
\hline
\end{tabular}

Thermal conductivity measurements were performed by the comparative rod analysis method (ASTM E1225, "Standard Test Method for Thermal Conductivity of Solids by Means of the Guarded-Comparative-Longitudinal Heat Flow Technique") and FMI IPOS 08-08-20, “Thermal Conductivity Test Procedure: Comparative Flat Slab Method". The test specimens were instrumented with thermocouples in grooves on the top and bottom faces. As shown in Figure 5, the specimens were mounted between two metering samples of the reference material (NIST standard). This stack was longitudinally positioned between a set of top and bottom heaters and associated heat sinks. A thermal 
guard heater was placed around the test stack to minimize radial heat flow, and insulation was installed to surround the setup. The entire stack was enclosed by a glass bell jar, and then evacuated and backfilled with the test gas, 0.2 atm argon. Measurements and calculations were conducted in accordance with ASTM E1225.

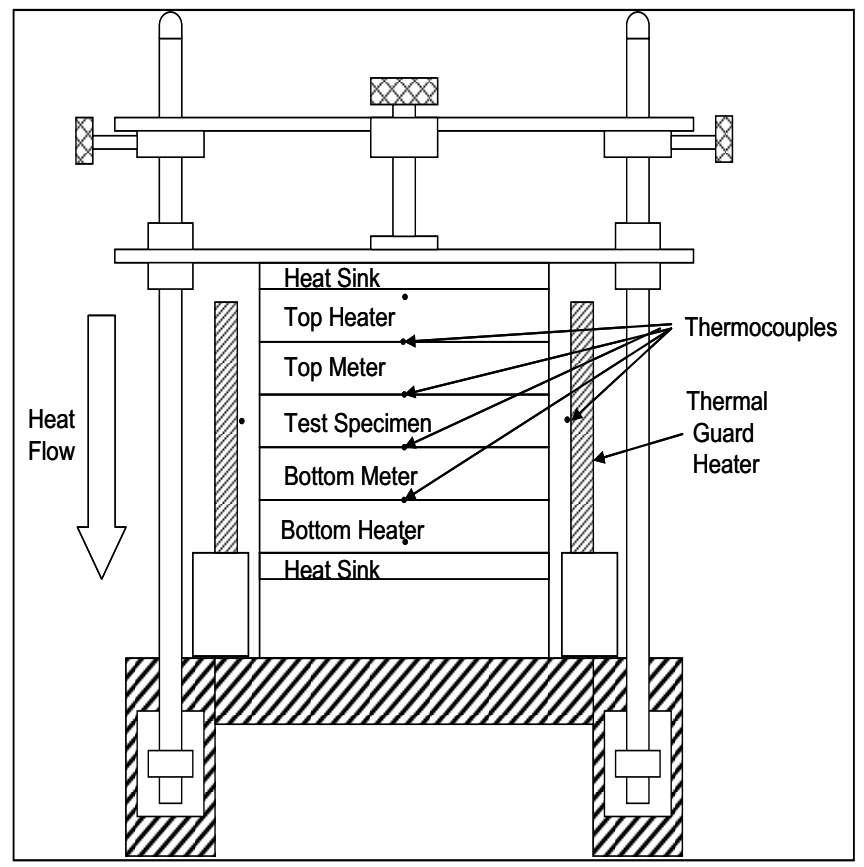

Figure 4. Steady-state Comparative Flat Slab Thermal Conductivity Apparatus

Through-thickness thermal conductivity test results are presented in Table 3, listing specimen ID, thermal conductivity at $100^{\circ} \mathrm{F}$, and thermal conductivity at $350^{\circ} \mathrm{F}$. Comparing these results to MSL/M2020 production data, average MSL/M2020 LAT measurements were: $1.22 \mathrm{BTU}-$ in $/ \mathrm{hr}-\mathrm{ft}^{2}-{ }^{\circ} \mathrm{F}$ at $100^{\circ} \mathrm{F}$ and $1.66 \mathrm{BTU}-\mathrm{in} / \mathrm{hr}-\mathrm{ft}^{2}-{ }^{\circ} \mathrm{F}$ at $350^{\circ} \mathrm{F}$. lyocell-based PICA average results in Table 3 were 0.939

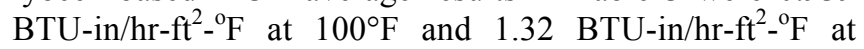
$350^{\circ} \mathrm{F}$. These results were lower than average LAT results for production rayon based PICA, but not out of range of the overall variation of production PICA. LAT results have ranged from 0.82 to $1.91 \mathrm{BTU}-\mathrm{in} / \mathrm{hr}^{-\mathrm{ft}^{2}-}{ }^{\circ} \mathrm{F}$ at $100^{\circ} \mathrm{F}$ and from


replicates are necessary to make conclusions of measurement values and variation, this data exhibits very comparable results to heritage rayon derived PICA.
Table 3. Summary of Lyocell PICA Thermal Properties

\begin{tabular}{|c|c|c|c|}
\hline \multirow{2}{*}{$\begin{array}{c}\text { Lyocell } \\
\text { Billet } \\
\text { ID }\end{array}$} & $\begin{array}{c}\text { Lyocell } \\
\text { Specimen } \\
\text { ID }\end{array}$ & \multicolumn{2}{|c|}{$\begin{array}{c}\text { Thermal } \\
\text { Conductivity } \\
\text { BTU-in/hr-ft }{ }^{2}{ }^{\mathbf{}} \mathbf{F}\end{array}$} \\
\cline { 3 - 4 } & at $\mathbf{1 0 0}^{\circ} \mathbf{F}$ & $\mathbf{a t}^{\mathbf{3 5 5}}{ }^{\circ} \mathbf{F}$ \\
\hline \multirow{2}{*}{ LI-5 } & LI-6-TC-01 & 1.25 & 1.86 \\
\cline { 2 - 4 } & LI-6-TC-02 & 1.08 & 1.62 \\
\hline \multirow{2}{*}{ LI-6 } & LI-5-TC-01 & 0.836 & 1.13 \\
\cline { 2 - 4 } & LI-5-TC-02 & 0.824 & 0.978 \\
\hline \multirow{2}{*}{ LI-7 } & LI-7-TC-01 & 0.805 & 1.09 \\
\cline { 2 - 4 } & LI-7-TC-02 & 0.836 & 1.22 \\
\hline \multicolumn{2}{|c|}{ Lyocell PICA Average } & $\mathbf{0 . 9 3 9}$ & $\mathbf{1 . 3 2}$ \\
\hline \multicolumn{2}{|c|}{ Rayon PICA Average } & $\mathbf{1 . 2 2}$ & $\mathbf{1 . 6 6}$ \\
\hline
\end{tabular}

\section{SUMMARY}

PICA manufactured from a lyocell precursor, a domestic rayon alternative, has proven to be comparable to heritage material and FMI has demonstrated manufacturing both fiberform and PICA in billet form as well as a net shape cast unit. lyocell derived PICA is within the density specification of standard (heritage) PICA. Preliminary arc-jet testing at three conditions on a limited number of coupons, spanning the anticipated low to high potential application range for PICA indicate that lyocell PICA behavior is in family with heritage material having comparable recession and thermal response, however the presence of a dulling agent slightly influenced the emissivity of the lyocell derived material. Initial mechanical and thermal properties are in family with heritage rayon PICA. From these preliminary results lyocell PICA is likely a "drop in" replacement for future NASA mission needs. Since lyocell is manufactured in the US in very large quantities and the need is in the commercial sector, lyocell based PICA could be a sustainable source for future mission needs.

\section{FUTURE WORK}

With recent arc jet test completion, the material response of lyocell derived PICA needs to be compared to expected performance using the heritage PICA thermal response model in FIAT. Further post arc jet coupon characterization is in progress. With recession measurements complete, coupons will be CT scanned to look for any off-nominal internal behavior followed by sectioning to determine char depth and compare to predicted values. Limited property testing is still ongoing at FMI. The char composition in both PICA variants will also be compared to assess if different impurities in lyocell impact performance. While initial work has demonstrated the viability of lyocell derived PICA, additional work is required to verify it as a drop-in replacement. 


\section{ACKNOWLEDGEMENTS}

The authors thank NASAs Space Mission Directorate Planetary Science Division for funding this project. Authors also acknowledge Dr. Y-K Chen, M. Olson and G. Gonzales for assistance with arc jet coupon design and test execution.

\section{REFERENCES}

[1] Tran, H.K., "Phenolic Impregnated Carbon Ablators (PICA) for Discovery Class Missions", AIAA Paper 961911, June 1996.

[2] Wilcockson, W., "Stardust Sample Return Capsule design experience", 7th AIAA/ASME Joint Thermophysics and Heat Transfer Conference, AIAA paper \# 2854, 1998.

[3] Lyocell (n.d.) In How Products are Made. Retrieved on Oct $11^{\text {th }}$ 2017, from http://www.madehow.com/Volume$\underline{\text { 5/Lyocell.html }}$

[4] Lenzing, (n.d.) In Business Insider. Retrieved on Oct $11^{\text {th }}$ 2017, from http://www.businessinsider.com/how-tencelcompares-to-cotton-2015-9

https://www.youtube.com/watch?time continue $=450 \& \mathrm{v}=$ $\underline{\text { X6wp1ST2Jas }}$

[5] Chen, Y.-K. and Milos F.S., "Ablation and Thermal Response Program for Spacecraft Heatshield Analysis," Journal of Spacecraft and Rockets, Vol. 36, No. 3, 1999, pp. $475-483$.

[6] Andreoli, C. and Freti, F., Reference Books of Textile Technology: Man-made Fibres, Publisher: Woodhead Publishing; 1 edition (January 15, 1984)

\section{BIOGRAPHY}

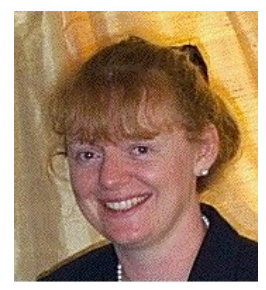

Dr. Mairead Stackpoole is the Branch Chief of the Thermal Protection Materials Branch at NASA Ames Research Center. She is the NASA Ames technical lead for the PICA sustainability project and has over 15 yrs. experience in TPS development, manufacturing and characterization. She obtained her Ph.D. from the University of Washington in Materials Science and Engineering.

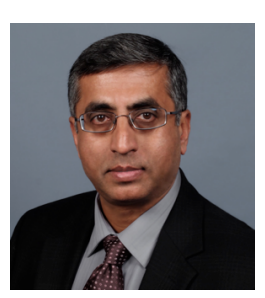

Dr. Ethiraj Venkatapathy is the Chief Technologist for the Entry Systems and Technology Division at NASA Ames Research Center. He is also the Project Manager for the Advanced TPS Materials (TPSM) program funded by the Game Changing Development Program of the Space Technology Mission Directorate, NASA HQ. He is an Associate Fellow of Ames. He obtained his Ph.D. from Iowa State University in Aerospace Engineering and his Bachelor of Technology from Indian Institute of Technology, Madaras, India



Dr. Steven Violette received his Ph.D. in Chemical Engineering from the University of Maine in 2003. He is a senior scientist in the Application Engineering team at Fiber Materials Incorporated. His focus is the development of advanced composite materials and their manufacturing

processes. In eleven years of high temperature composites experience at FMI, he has been the principle investigator and program manager for contracts to NASA, US Air Force, Army, Boeing, Lockheed Martin, Honeywell, and other aerospace companies. In these programs, he has been responsible for the development of thermal protection and propulsion products, including Carbon-Carbon, Carbon-Silicon Carbide, Polymer Matrix Composites, and lightweight ablators including Phenolic Impregnated Carbon Ablator. Prior to joining FMI, Dr. Violette worked for Georgia-Pacific, Sappi, James Hardie Corporation, and the University of Maine's Industrial Development Center. 
